\title{
USING THE AHP TO ESTABLISH INCLUSIVE HOUSING DEVELOPMENT PRIORITIES FOR INDUSTRY
}

\begin{abstract}
The lack of inclusive housing options across the developed world means that many people with disability reside in housing which does not meet their physical and cognitive accessibility requirements, as well as their social and health care needs. This situation is partly due to a) a lack of understanding by designers and developers about what consumers want from their housing beyond the necessary physical access features and b) lack of multidisciplinary understanding of the various decisions or motivating drivers that might result in a development opportunity. In order to provide some decision clarity for the complex area of inclusive housing development, an AHP was used to determine the key priorities across a multidisciplinary group of stakeholders, including architects and designers, builders, disability service organisation professionals, and occupational therapists and access consultants. Despite some discipline variability, AHP results indicated three key drivers common to all stakeholder groups, namely, 'connectedness of end users', 'feasibility' and 'building specifications'. The findings assert the importance of considering the needs of end users for inclusive housing development, a consideration that is often overlooked. The findings of this study will assist development of a resource manual to assist industry throughout inclusive housing development decision-making.
\end{abstract}

Keywords: inclusive housing, disability, health and social care

\section{Introduction}

Access to adequate housing is a human right, and a determinant of health (see United Nations [UN], 1948, 1976a, 1976b). Housing that is suitable for people with disability can be defined as inclusive housing, which refers to residential dwellings that aim to meet the diverse needs of people irrespective of their stage in life (Milner \& Madigan, 2004). Specifically, inclusive housing designs must consider physical and cognitive accessibility, social accessibility, and health care support for end users (Lakhani \& Zeeman, 2016). Access to inclusive housing is especially important for people with disability as recent research has established that housing has considerable impact on the ability for people with disability to engage with the community and live independently (Granbom, Iwarsson, Kylberg, Pettersson, \& Slaug, 2016; Greiman \& Ravesloot, 2016; Hammel et al., 2015).

The shortage of inclusive housing across the developed world is a pressing issue and an undersupply of inclusive housing means that many individuals with disability reside in housing which is not adequate for their needs (National Disability Services [NDS], 2015; Muscular Distrophy United Kingdom [MDUK]; Joint Center for Housing Studies [JCHS], 2015). The limited supply of, and inadequacy of, inclusive housing is due to a variety of factors including public and private financial constraints, individual socio-economic 
constraints and a lack of co-ordination across the public and private sectors (NDS, 2015; MDUK, 2015). In part, poor levels of housing are a result of the complexity involved with inclusive housing development and/or home modification decisions. Inclusive housing development and home modification decisions require the coordination of various stakeholders including but not limited to architects, disability support services, private construction, health professionals, and most importantly, service users and their family and carers. All groups have differing priorities, and the priorities of many stakeholders are unaccounted for throughout the inclusive housing development process and disability literature.

\section{Literature Review}

A systematic review guided by the PRISMA approach (Moher, Liberati, Tetzlaff, \& Altman, 2009) was undertaken to establish how the AHP has been used to inform inclusive housing development decisions. Literature was searched over two periods. Initially, on 26 August 2015, the databases, CINAHL, ISI WebofScience, PubMed, PsychInfo and Avery were searched for literature published at any date using the following search string: ("disab*" OR "Support* Living" OR "Support* Hous*") AND ("AHP" OR "Analytic Hierarchy Process" OR "pairwise comparison*" OR "eigenvector" OR "eigenvalue"). Lakhani and Zeeman (2016) presented their findings from this search, and two potential AHP hierarchies for inclusive housing development at the 2016 International Symposium of the Analytic Hierarchy Process. Of the 435 sources identified, zero specifically investigated the use of AHP for inclusive housing development. While two studies that closely met the selection criteria focused on the use of an AHP to identify important factors relating to health services for specialised populations, namely, empowering elderly people to be actively involved in their health (Fico, Gaeta, Arredondo, \& Pecchia, 2015), and identifying risk factors which contribute to falls in elderly populations (Pecchia, Bath, Pendleton, \& Bracale, 2011). An updated identical search was conducted on the 5th April 2017 to identify all relevant articles published since the initial search. This search produced an additional 91 sources for review, and zero focused directly on the use of AHP for inclusive housing development decisions.

\section{Objectives}

As indicated by Lakhani and Zeeman (2016), the AHP can be used to establish the priorities that diverse stakeholders have for inclusive housing development. Consequently, this Australian Research Council [LP140100446] and industry funded study investigated the priorities that architects, builders, occupational therapists, and disability service organisation management had concerning inclusive housing development.

\section{Research Design/Methodology}

A single goal AHP model with three levels was utilised to answer the question: "What are the most important drivers for inclusive housing development?" Drivers were determined via a two stage sequential process. First, a systematic review of peer-reviewed literature was undertaken to identify drivers important for inclusive housing development. Second, stakeholders $(n=130)$ completed a cross-sectional survey to confirm the importance of these drivers and indicate drivers which may have not been identified via the initial search. The hierarchy has been included in Table 1 below. 
Table 1: AHP Hierarchy to establish important inclusive housing development drivers

\begin{tabular}{|c|c|c|c|}
\hline Level 0 & Level 1 & Level 2 & Level 3 \\
\hline \multirow{18}{*}{$\begin{array}{l}\text { "What are the most } \\
\text { important drivers } \\
\text { for inclusive } \\
\text { housing } \\
\text { development?" }\end{array}$} & \multirow[t]{8}{*}{$\begin{array}{l}\text { Building } \\
\text { Considerations }\end{array}$} & \multirow[t]{4}{*}{ Building Specifications } & $\begin{array}{l}\text { Building } \\
\text { Standards/Requirements }\end{array}$ \\
\hline & & & $\begin{array}{l}\text { Clear Objectives from End } \\
\text { Users }\end{array}$ \\
\hline & & & Future Adaptability \\
\hline & & & User Preferences \\
\hline & & \multirow[t]{4}{*}{ Design Specifications } & Domestic Décor \\
\hline & & & $\begin{array}{l}\text { Inside and Outside } \\
\text { Accessibility }\end{array}$ \\
\hline & & & Dwelling Functionality \\
\hline & & & Visitability \\
\hline & \multirow[t]{5}{*}{ Feasibility } & Building or Design Budget & \\
\hline & & Re-sale potential & \\
\hline & & Practicality/Constructability & \\
\hline & & Market Demand & \\
\hline & & Rental/Mortgage Affordability & \\
\hline & \multirow{5}{*}{$\begin{array}{l}\text { Connectedness of } \\
\text { End User }\end{array}$} & Type of area/location & \\
\hline & & Community Engagement & \\
\hline & & Proximity to Transport & \\
\hline & & Security & \\
\hline & & Access to Healthcare & \\
\hline
\end{tabular}

\section{Data/Model Analysis}

Twenty-nine professionals involved in inclusive housing development - designers and architects $(n=12)$, builders $(n=7)$, occupational therapists and access consultants $(n=6)$, and disability service organisation management $(n=4)$ - conducted pairwise comparisons using a 1-9 AHP scale. Data was collected, and geometric means calculated via the software Decision Lens.

Figure 1 provides weights for each Level 1 factor. Results conclude that connectedness of end user was the most important factor group, with a weight of 44.1. Feasibility was the second most important factor group, and building specifications the third.

\section{Figure 1: Level one factor weights}

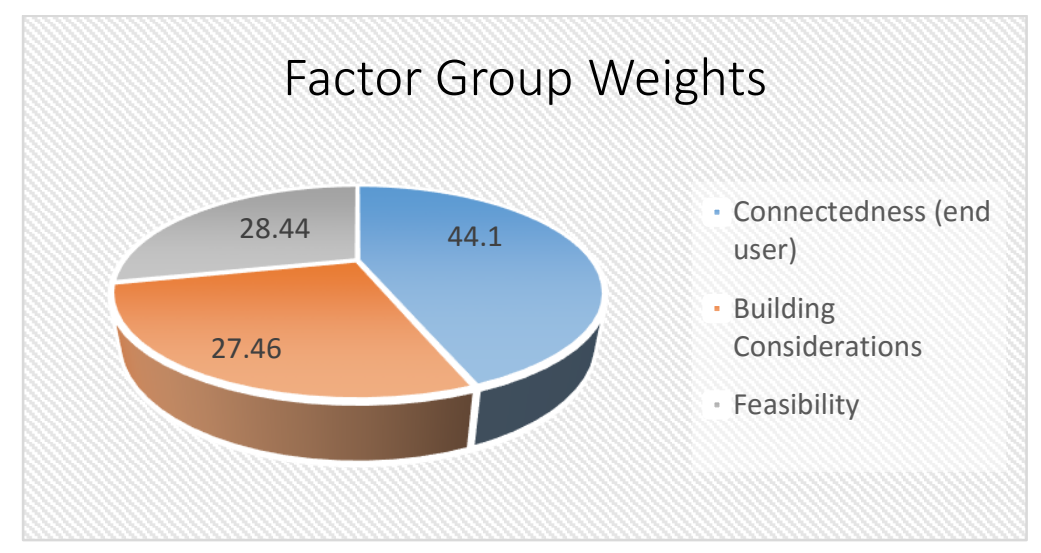


Global weights for each driver have been included in Table 2 below. As indicated, access to health care, community engagement, proximity to transport, practicality/constructability and dwelling functionality were the five highest weighted drivers.

Table 2: Global weights for each driver

\begin{tabular}{|c|c|c|c|}
\hline Factor Group & Sub Group & Child Drivers & Weights \\
\hline \multirow[t]{8}{*}{$\begin{array}{l}\text { Building } \\
\text { Considerations }\end{array}$} & \multirow[t]{4}{*}{$\begin{array}{l}\text { Building } \\
\text { Specifications }\end{array}$} & $\begin{array}{l}\text { Building } \\
\text { Standards/Requirements/Guidelines }\end{array}$ & 1.58 \\
\hline & & $\begin{array}{l}\text { Clear Objectives/End User Needs } \\
\text { (functional design elements) }\end{array}$ & 4.4 \\
\hline & & Future Adaptability & 2.66 \\
\hline & & $\begin{array}{l}\text { End User Preferences (interior and } \\
\text { exterior design elements) }\end{array}$ & 2.16 \\
\hline & \multirow{4}{*}{$\begin{array}{l}\text { Design } \\
\text { Specifications }\end{array}$} & Domestic Décor & 1.83 \\
\hline & & Inside and Outside Access & 5.59 \\
\hline & & Dwelling Functionality (for end users) & 6.34 \\
\hline & & Visitability & 2.89 \\
\hline \multirow{5}{*}{$\begin{array}{l}\text { Connectedness (of } \\
\text { end user) }\end{array}$} & & Type of area/location & 3.79 \\
\hline & & Community Engagement & 11.09 \\
\hline & & Proximity to Transport & 10.54 \\
\hline & & Security & 6.61 \\
\hline & & Access to Healthcare & 12.06 \\
\hline \multirow[t]{5}{*}{ Feasibility } & & Building or Design Budget & 6.01 \\
\hline & & Re-sale potential & 2.91 \\
\hline & & Practicality/Constructability & 8.81 \\
\hline & & Market Demand & 5.1 \\
\hline & & Rental or Mortgage Affordability & 5.62 \\
\hline
\end{tabular}

Connectedness to end user was considered a priority driver, as defined by access to healthcare, community engagement, and proximity to transport. This was judged to be more important than feasibility drivers and building specifications. These findings have important implications for practice and training in the fields of design, development and construction.

\section{Limitations}

A diverse set of stakeholders are involved throughout inclusive housing development decisions. In the future it will be important to consider the perspectives of additional stakeholders including government public housing representatives and rental agency employees.

\section{Conclusions}

The results emphasise the importance of connectedness of end users as a driver for inclusive housing development decisions. Given that inclusive housing development decisions are often made without considering end user perspectives (Wright, 
Muenchberger, \& Whitty, 2015), and housing developers admit to being unaware of end user preferences and requirements (Imrie, 2003; Imrie \& Hall, 2001), current findings provide important clarity around the nature of end-user motivations to guide future design and development decisions.

\section{Key References}

Fico, G., Gaeta, E., Arredondo, M. T., \& Pecchia, L. (2015). Analytic Hierarchy Process to Define the Most Important Factors and Related Technologies for Empowering Elderly People in Taking an Active Role in their Health. J Med Syst, 39(9), 300. doi:

10.1007/s10916-015-0300-9

Hammel, J., Magasi, S., Heinemann, A., Gray, D. B., Stark, S., Kisala, P., . . Hahn, E. A. (2015). Environmental Barriers and Supports to Everyday Participation: A Qualitative Insider Perspective From People With Disabilities. Arch Phys Med Rehabil, 96(4), 578588. doi: 10.1016/j.apmr.2014.12.008

Lakhani, A., \& Zeeman, H. (2016). Analytic Hierarchy Process to Inform Inclusive Housing Development: Two Applications. Paper presented at the International Symposium of the Analytic Hierarchy Process, London, U.K.

Pecchia, L., Bath, P. A., Pendleton, N., \& Bracale, M. (2011). Analytic Hierarchy Process (AHP) for examining healthcare professionals' assessments of risk factors. The relative importance of risk factors for falls in community-dwelling older people. Methods Inf Med, 50(5), 435-444. doi: 10.3414/me10-01-0028

Milner, J., \& Madigan, R. (2004). Regulation and innovation: rethinking 'inclusive' housing design. Housing Studies, 19(5), 727-744. doi: 10.1080/0267303042000249170 